\title{
8.P12
}

\section{Functional Heterogeneity of the Striatum in a Rodent Model of Huntington's Disease: Considerations for Neurological Transplantation}

\author{
E.E. Concepcion and W.C. Low \\ Departments of Neurosurgery and Physiology, and Program in Neuroscience, \\ University of Minnesota Medical School, Minneapolis, MN 55455, USA
}

Recent studies utilizing a neurotoxic model of Huntington's disease (HD) in rodents have demonstrated locomotor abnormalities following unilateral lesions of the striatum. The behavioral abnormalities are manifested as an asymmetric rotation ipsilateral to the side of the lesion following apomorphine administration. The current study provides evidence for the dependence of rotational direction on the site of the striatal lesion and suggests factors for consideration in utilizing similar models in future neural transplantation research.

Twelve Sprague-Dawley rats were given lesions of the right striatum using stereotaxic injections of quinolinic acid (QA) (150 nmole in $1 \mu$ l saline). One group of rats $(\mathrm{n}=4)$ received injections at AP $3.0 \mathrm{~mm}$, ML $2.5 \mathrm{~mm}$ (with respect to bregma), and DV $4.5 \mathrm{~mm}$ (with respect to the dural surface). A second group $(n=4)$ received striatal injections at AP $1.4 \mathrm{~mm}$, ML 3.3 $\mathrm{mm}$, and DV $4.5 \mathrm{~mm}$. A third group $(\mathrm{n}=4)$ received striatal injections at AP $-0.2 \mathrm{~mm}$, ML 4.25 $\mathrm{mm}$, and DV $4.0 \mathrm{~mm}$. The behavioral effects of apomorphine administration $(1 \mathrm{mg} / \mathrm{kg}$, s.c. $)$ were examined one month after the lesion (see Figures 1 and 2). Animals with anterior striatal lesions (AP $3.0 \mathrm{~mm}$ ) displayed rotational biases contralateral to the side of the lesion $(75 \pm 13$

\section{Ipsi- \& Contralateral Rotation \\ Following Apomorphine Injection}

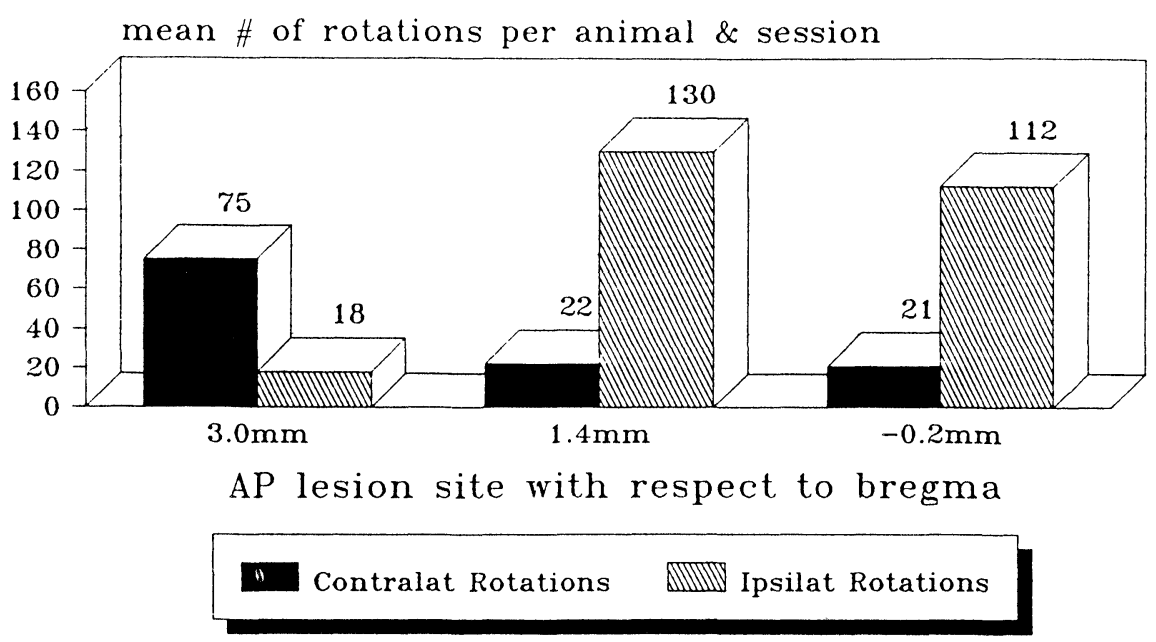

data based on three $70 \mathrm{~min}$ sessions

Figure 1 


\section{Rotational Bias Between Lesion Sites}

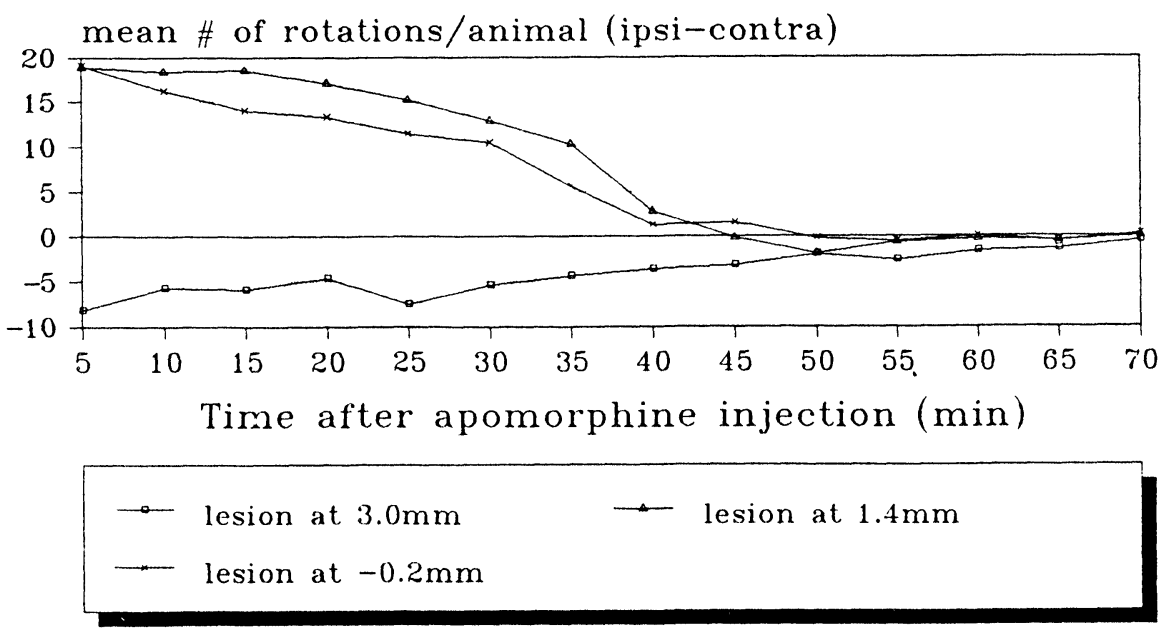

Figure 2

contralateral rotations vs. $18 \pm 4$ ipsilateral rotations per animal averaged across three 70 minute sessions) whereas animals with more posterior lesions at AP $1.4 \mathrm{~mm}$ or $-0.2 \mathrm{~mm}$ exhibited an ipsilateral rotational bias $(130 \pm 25$ ipsilateral rotations vs. $22 \pm 4$ contralateral rotations and $112 \pm 21$ ipsilateral rotations vs. $21 \pm$ 4 contralateral rotations, respectively). Analysis of variance revealed significant group effects $(p$ $<0.05$ ). Post-hoc pair-wise comparisons revealed that animals with AP $1.4 \mathrm{~mm}$ and AP -0.2 $\mathrm{mm}$ did not differ in their rotational bias. Both of these groups, however, differed in their rotational biases in comparison to animals with AP $3.0 \mathrm{~mm}$ injections of quinolinic acid $(\mathrm{p}<$ 0.05 ). These results reflect a possible heterogeneity of locomotor function in the rodent striatum along its rostro-caudal axis. These findings stress the importance of preselecting a particular lesion site and becoming familiar with differential behavioral characteristics associated with ablations of this area. (Supported by NIH RO1-NS-24464). 

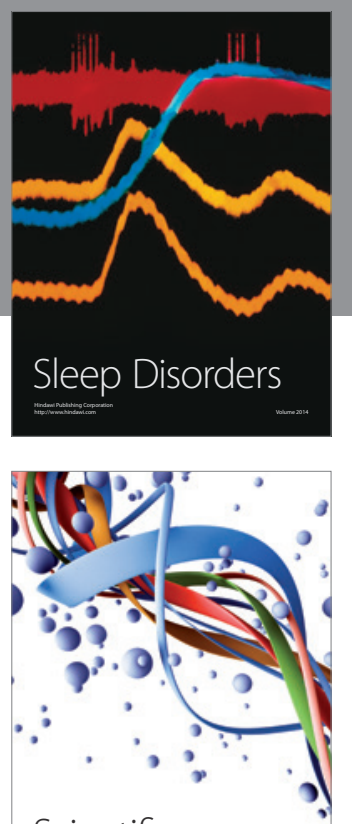

Scientifica
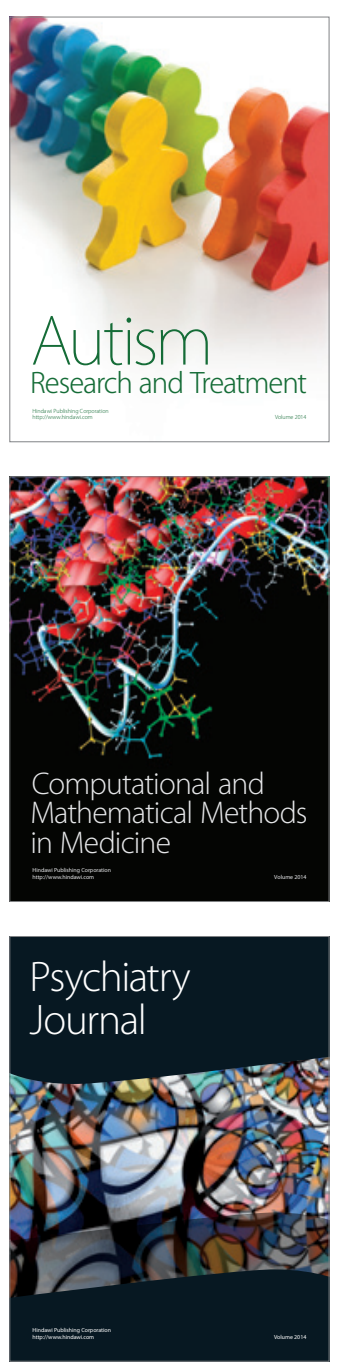
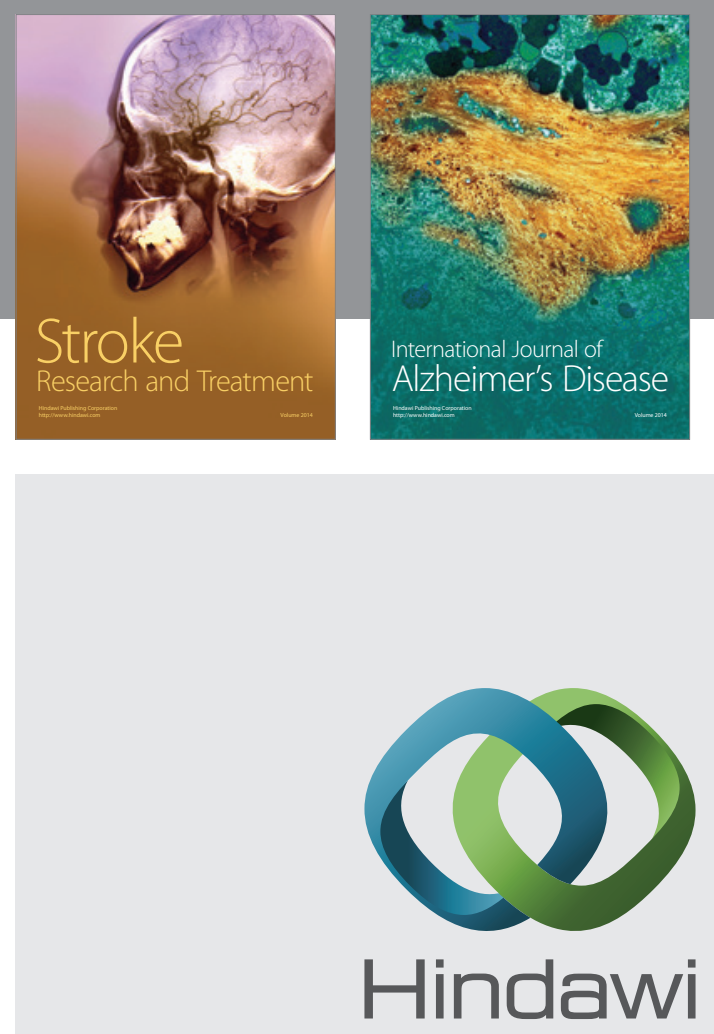

Submit your manuscripts at

http://www.hindawi.com
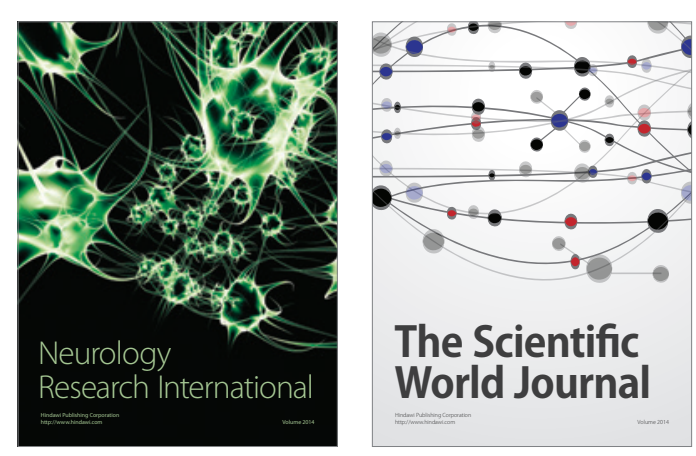

The Scientific World Journal

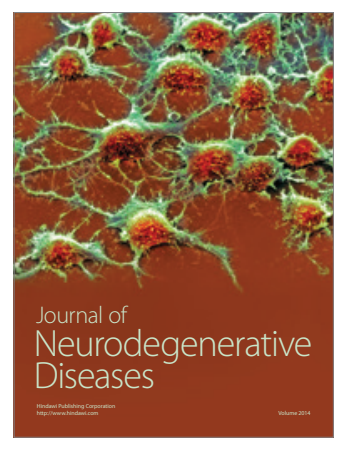

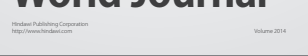

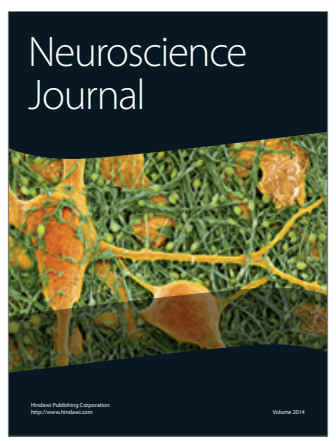

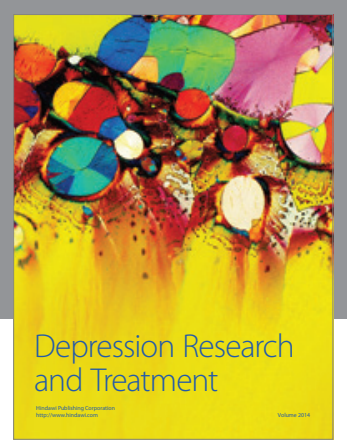
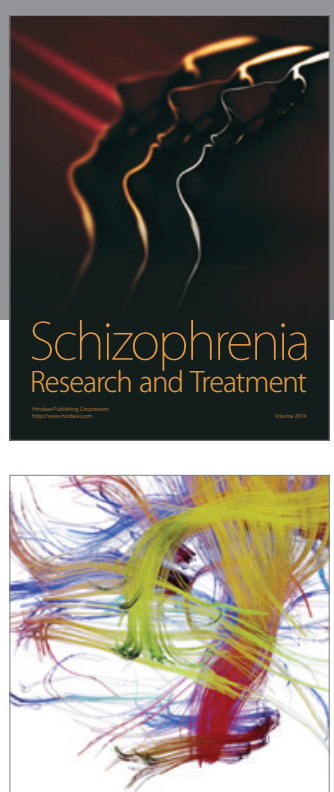

Brain Science

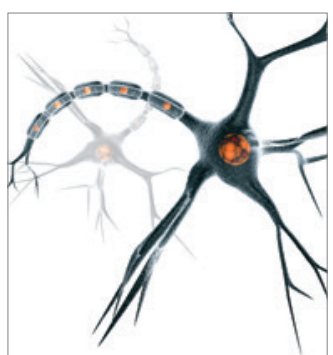

Neural Plasticity
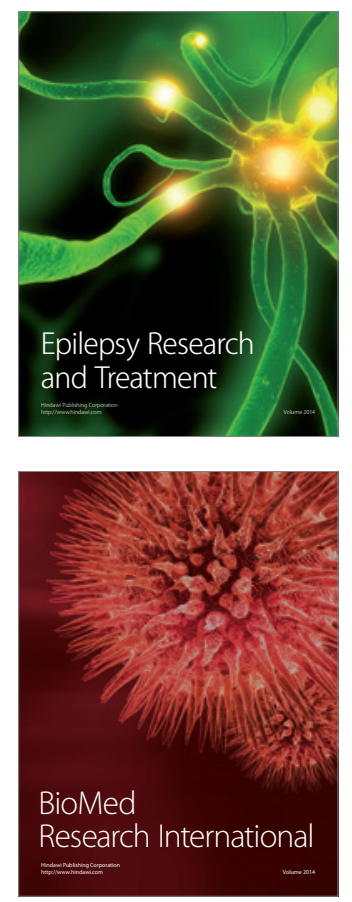

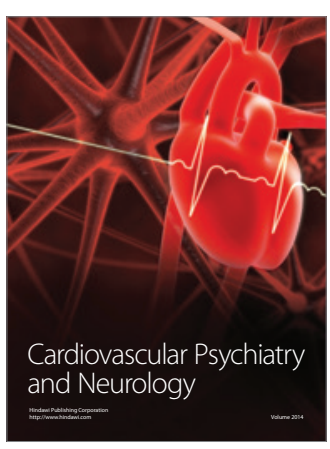

Parkinson's

Disease
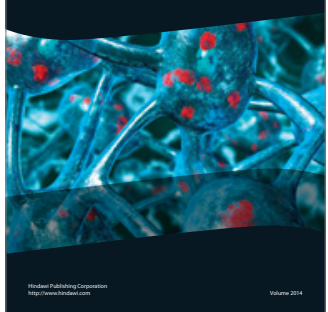